\title{
Anti-Money Laundering Regulation of China's Mobile Payment and Settlement Industry
}

\author{
Yanwei Wang, Yangchao Ou \\ School of Economics and Management, Southwest Jiaotong University, Chengdu, China \\ Email: wyw.1980@163.com
}

Received 14 October 2015; accepted 22 November 2015; published 25 November 2015

Copyright $@ 2015$ by authors and Scientific Research Publishing Inc.

This work is licensed under the Creative Commons Attribution International License (CC BY). http://creativecommons.org/licenses/by/4.0/

(c) (i) Open Access

\begin{abstract}
In recent years, with the continuous advance of payment equipment and technologies like China's internet Finance, Big Data and Mobile Network, the anonymity, rapidity and cross-border transaction of mobile payment business have also brought many money laundering risks. Therefore, it is necessary to strengthen cooperation with the supervision organization of international payment and anti-money laundering business, and meanwhile to constantly improve the supervision mechanism of China's payment and anti-money laundering business.
\end{abstract}

\section{Keywords}

China, Mobile Payment Clearing, Anti-Money Laundering

\section{Introduction}

In recent years, with the development of China's mobile payment and clearing equipment, technologies like big data, mobile network, business model on payment and settlement industry and financial institutions, commercial service providers, users constantly enrich. The cross-industry, cross-agency, cross-border makes mobile payment and settlement make product form and functions of services continue to expand substantially [1]. China's mobile payment services keep the continuous growth trend which plays an important role in our daily life. In 2014, the number of electronic payment services amount to 33 million times, totaling ¥140 billion. Compared with the number of last year, total payment achieves an increase of $29.28 \%$ and $30.65 \%$ respectively.

The sheer number of data on payment and settlement industry provides the access to promoting great convenience for social economy, so that the great characteristic, such as convenience and timeliness, increasingly attracted widespread attention in the international financial community [2] [3]. However, the characteristic like 
anonymity, speed and relatedness on mobile payment and settlement also attracts international anti-money laundering organization attention. International anti-money laundering organization has enacted a series of guidance documents about a mobile payment and clearing. In March 2012, People’s Bank of China issued the "the institution management approach about anti-money laundering and terrorist financing payment”. In the new situation, it is meaningful and valuable to do research in anti-money laundering regulation of China's mobile payment and settlement and constantly improve the supervision mechanism of China's payment and anti-money laundering business [4] [5].

\section{Risk Assessment on China's Mobile Payment and Settlement Industry Money-Laundering}

All kinds of convenient mobile payment tools, such as memory cards, credit cards, electronic wallet have been used in our daily life. Internet payment methods continuously have relevance to the method of anti-moneylaundering, forming a potential source of money-laundering risk [6].

1) The main types of mobile payment and settlement of money-laundering:

Money laundering in the banking network. The actual beneficiary or control people use forged evidences to open a bank account in the banking network, aiming at evading supervision of financial institutions in the real environment. The tool of mobile payment and settlement can be used to transfer a large amount of money. We have uncovered a lot of money-laundering cases of Internet banking laundering

Money laundering in the virtual currency. Virtual currency can be divided in to two categories. The first one is issued by non-financial institutions, such as Q coins and game currency, product Discount coins, which can be traded between the network and reality [7]. The other is issued by International network of developers, such as Amazon coin, Bit coin and Lite Coin. Silk Road network is a typical website which be use for money laundering [8].

Money laundering in online financial services. With the continuous advance of online financial services, various tools of mobile payment, such as loans, insurance, securities, P2P, have been used to conceal its true origin and transfer illegal income rapidly.

Metal and artwork exchange in Cash intensive transactions. Using all kinds of platform of network transactions where Metal and artwork exchange in Cash intensive transactions are the main subject matter of the transaction. In order to evade anti-money laundering regulation, launderers employ or control others to come forward operating transactions. This phenomenon has become of vulnerable regions on China's mobile payment and settlement which FATF pay more attention to [9].

Gambling in the Internet money laundering. Launderers exe cute all kinds of money-laundering through online gambling, phishing, and other forms of Network Marketing. In some parts of the countries with weak anti-money laundering regulation, Launderers make use of financial accounts to transfer funds crazily.

2) Money laundering risk source of mobile payment and settlement

It is an important part of anti-money laundering supervision in mobile payment and settlement industry that depth analysis risk source of the money laundering, and risk assessment of risk sources, so according to the degree of risk to take different regulatory measures.

All kinds of idle excessive payment cards is a potential source of money-laundering risks. By the end of 2013, the cumulative annual bankcard issuing 4.214 billion, live card rate is $40 \%$; the cumulative debit card issuing volume 3.823 billion, live card rate is 38\%; the cumulative amount of the credit card issuing is 391 million, live card rate is $46 \%$. As part of the financial institution pursue the card issuing volume to expand market share, promoting bank cards in various forms that resulting in the accumulation of a huge amount of idle bank cards. The idle bank card is becoming a money-laundering criminal scoveted objects. Apart of the idle bank cards become a money laundering criminals' underground market (or purchase, or lease) so that these idle payment cards become important tools of crime of corrupt money-laundering, fraud money laundering, underground banks laundering. In the case of various types of money laundering crime seized by Ministry of Public Security, the idle bank cards and credit cards are called the tools of crime.

The continuous innovation of cross industry payment model has formed a potential risk of money laundering. It is easy to form a potential money laundering risk source, because business model of payment and settlement industry is constantly innovation, trading volume continues to hit a new high, especially mobile network communications equipment manufacturers, financial institutions payers, commercial service providers, and user 
payment methods increasingly interconnected, but they are inter regulatory standards, data systems are not homogeneous. Therefore, comprehensively promote the data depth integration of the device side, financial institutions, merchants, user, and scientific and reasonable to promote the establishment of the dynamic core of the money laundering risk assessment system is particularly important and must be studied.

The AML on-site inspections of payment and settlement industry exist regulatory loopholes. Since the payment and settlement industry is not just the payment and clearing agencies, but also involved in a number of commercial service providers, users and other transactions related parties, so there are many practical difficulties about AML on-site inspection. Such as the contents of the anti-money laundering on-site inspection, the internal control system construction and implementation of the AML, anti-money laundering organization construction of institutional, customer identification and transaction record keeping and so on. These are easy to form a new loopholes of anti-money laundering regulatory. We need to fully refine the Internet payment and settlement industry's anti-money laundering regulatory site inspection system, build evaluation criteria and the implementation details.

The rapid growth in the amount of cross-border payments is also formed a potential risk source of money laundering. With China's open economy has intensified, and the establishment of the free trade zone: Shanghai, Guangzhou, Tianjin and others, an increasing number of payment agencies and large international business platform, financial institutions, users reached a cooperation agreement, for example, Pay Ease and Apple, Amazon has signed online payment service agreement. In 2013, China domestic payments mechanism’s cross-border transactions of Internet payment reached ¥170 Million, the amount reached to ¥4838.8 billion. The huge cross-border payments finance has a consider able proportion of the trading partners is the international offshore financial center and other high-risk are as of money laundering and countries, due to the impact of administrative jurisdiction, judicial cooperation, money laundering intelligence assistance, etc. In particular, china is not a member The Egmont Group, there are important obstacles in anti-money laundering data exchange, resulting in potential risk sources of money laundering [10].

\section{China's Mobile Payment Clearing Mechanism Anti-Money Laundering Regulatory System Construction}

With the rapid development of Mobile payment and settlement services and the formation of many potential sources of risk of money laundering, it is necessary to build the regulatory system of anti-money laundering system.

1) The research about Supervision of international anti-money laundering organization in AML payment industry.

In February 2012, FATF published the "international standards on combating money laundering and the financing of terrorism \& proliferation” [1]. In the first recommendation, it is the first round clearly presented RBA (Risk-based approach) anti-money laundering regulatory guidelines, meanwhile, it also noted that every country should be based on national circumstances to analysis comprehensively the country's money laundering and terrorist financing risks, and to establish the regulatory system of money laundering and terrorist financing to adapt to the nature of risk. In addition, it should establish different levels of anti-money laundering regulatory measures according to different levels of risk.

The introduction of the guidance report, for the international anti money laundering sector has a landmark significance and value, marking the international anti-money laundering sector regulatory philosophy from "rulebased" to a "risk-based" .

Subsequently, FATF, FIUs, Basel and other international organizations did not stop there, but a further, then expand the system development and comprehensive improvement.

At the macro level of anti-money laundering, the FATF “risk-based” anti-money laundering regulatory concept has been widely recognized by the international community. In addition, UNODC, IMF, OECD use the "risk-based" anti-money laundering regulatory philosophy to guide its anti-money laundering work, and the reform anti-money laundering systems and specific measures. At the micro level of AML , FATF in the global anti money laundering regional organizations (FATF-Style Regional Body) to great assistance, on the one hand, the introduction constantly of diamond, gold, opium, non-governmental organizations (NGO), political sensitive people (Politically exposed person, PEP) and other specific regulatory guidance report to explore and improve the "risk-based" in various field of application; on the other hand, with the countries anti-money laundering fi- 
nancial Intelligence Centre (Financial intelligence units, FIU) as the center, through the fourth round of money-laundering mutual assessment, and constantly promote the national anti-money laundering data exchange, the case detective and other work.

2) AML regulatory guidance system

According to China's actual situation, to the international anti-money laundering organization concept and standards for external requirements, while PCAC (Payment \& Clearing Association of China,) and other industry associations to assist the People's Bank of China Anti-Money Laundering Office systems integration international anti-money laundering organization's guidance document, initiative report including the Chinese people's Bank of AMLFATF, Egmont Group, Wolfsburg Group, PCAC, UNODC, Basel, and as the core guiding philosophy and working methods. Meanwhile, the Chinese people's Bank of China's anti-money laundering data detection center for technical institutions to form anti-money laundering regulatory guidance mechanism of China's mobile payment and settlement system.

3) Anti-money laundering regulatory operate-mechanism system (as shown in Figure 1).

Anti-money laundering regulatory operate-mechanism system of mobile payment and settlement is an important part of the whole system, including mobile payment and clearing institution system, anti-money laundering internal control system and data analysis systems, payment and settlement data systems and account management system. It requires large data processing technology as the core to build two-way communication, smart analysis, scientific evaluation of the operating system. The system can track, capture, analysis and feedback massive transactions data to adapt to the increasingly large mobile payment and settlement business.

MSBs (Money Service Businesses), including Prepaid card, Internet payment services, Mobile Payment Services, Digital currencies and so on, forms a New Payment system (as shown in Figure 2).

Anti-money laundering internal control system and data analysis system. Anti-money laundering internal control system includes KYC (know you customer), DCC (Customer due diligence), and STRs (Suspicious transaction reports). The KYC requires various financial institutions ensure that the customer's true identity, record and maintain the authenticity and integrity and effectiveness of customer information when they provide services to customers. The DCC requires familiar with the customer's business scope and state, and financial transactions and other trading partners with due diligence. The STRs requires when customer financial transactions related to the characteristics of suspicious transactions report to the superior anti-money laundering investigation agencies. AML data analysis refers primarily to use of cluster analysis, correlation analysis, Time series analysis and other methods to analyze the mass transactions data generated by mobile payment and settlement institutions. FIUs uses the data analysis method sand anti-money laundering internal control system to

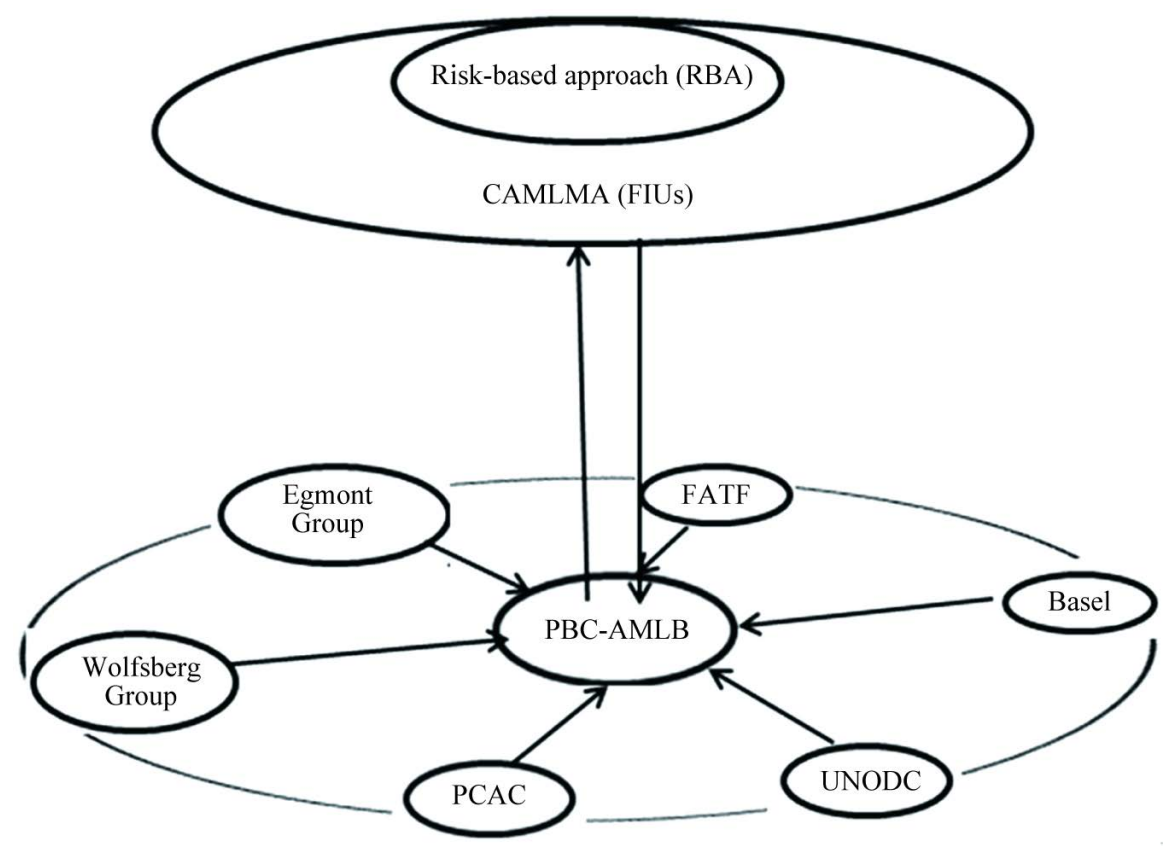

Figure 1. China AML regulatory guidance system. 


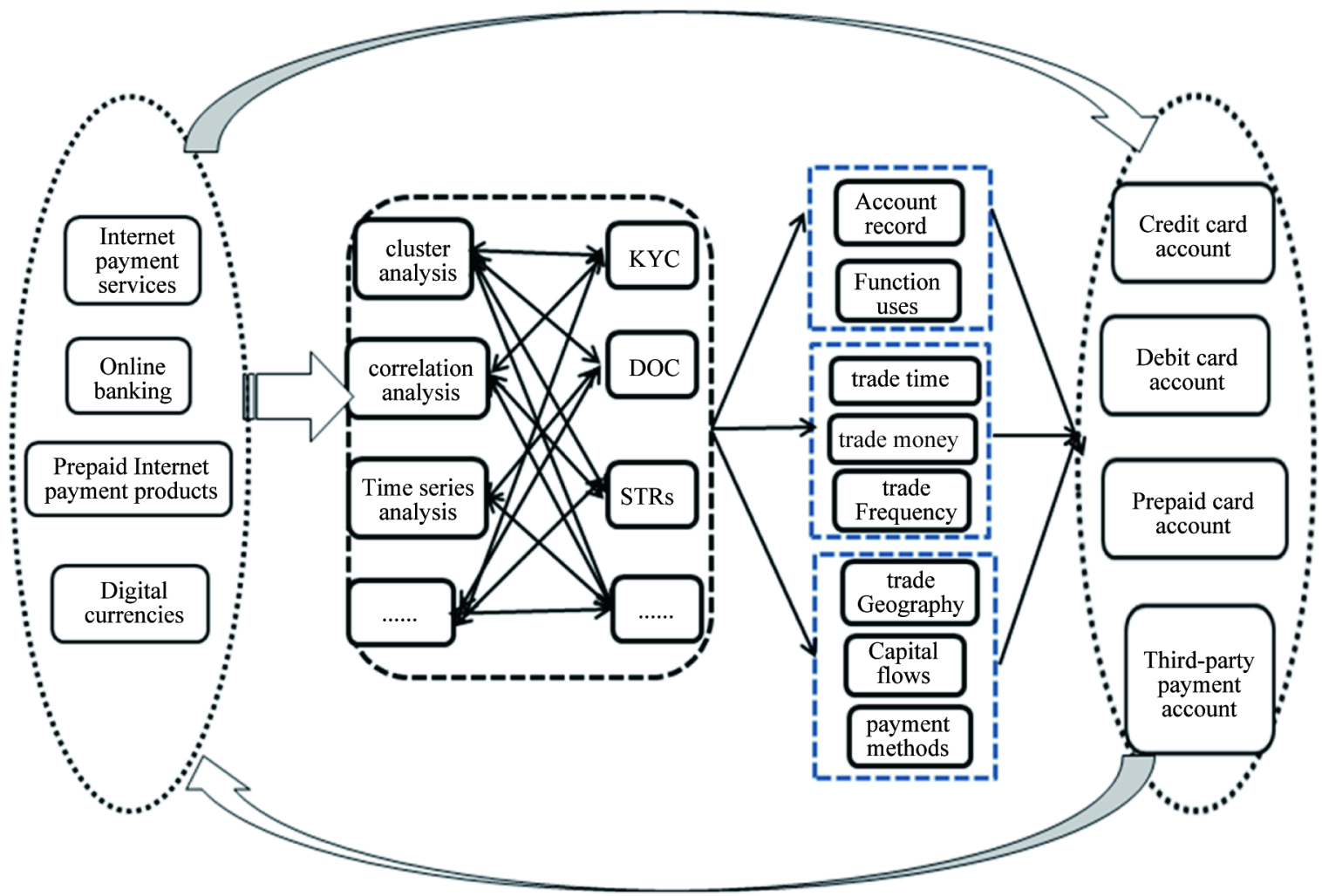

Figure 2. China mobile payment and settlement industry AML regulatory system.

systematic reform anti-money laundering data mining, and to monitor the entire mobile payment and settlement data.

Payment and settlement data system includes Accounts record, Function uses, Trade time, Trade money, Trade Frequency, Trade Geography, Capital flows, Payment methods and so on.

Accounts record: it requires to verify the true identity of the customer payment account, documented, and updated in accordance with the regulations, to maintain authenticity, dynamic and objectivity of the information.

Function uses: it requires tracking the use of common features after the customer's account is enabled, and to analysis the using differences and size compared to other companies in the industries using the difference in the payment account function.

Trade time: It requires tracking the customers and their trading partners both account dynamic, payment account transaction time changes and other basic transactions situation.

Trade money and frequency: It means to refer to the same type of customers, tracking the transaction size, frequency, change characteristics, etc. When the customer's account makes transaction with the counterparty in different time.

Trading partners: It requires tracking its payment account changes in trading partners after the customer's accounts is enable, including trading background, trading channels, transaction amounts and transaction frequency, etc.

Trade Frequency: We should make attention about the space location of customer account of the two parties to the transaction and the territorial administrative jurisdiction, especially in some regions of high incidence of money laundering.

Capital flows: It means we should make eyes on the two sides account funds to dynamic intransactions, usage and final destination, the actual beneficiaries and control people.

Payment methods: tracking all kinds of payment on customers’ accounts, such as NFC, two-dimensional codes, bar codes, pay and other forms of face to face, to analyze the abnormal situation on it.

Account management system, including Credit card accounts, Debit card account, prepaid card account, Third-party payment account, E-purse and so on. 


\section{Conclusion}

It can be expected that, with the rapid growth of China's mobile payment and settlement industry of business model innovation, mixed risk in money laundering will continue to highlight. This will require China to build innovative mobile payment and settlement industry's anti-money laundering regulatory risk assessment system clearing agencies, continue to resolve and eliminate high-risk areas, to enhance the effectiveness of China's mobile payment and settlement industry, anti-money laundering regulation.

\section{References}

[1] FATF (2012) Guidance Document: In the National Standards on Combating Money Laundering and the Financing of Terrorism \& Proliferation. 2012.2.

[2] FATF (2013) National Money Laundering and Terrorist Financing Risk Assessment. 2013.2.

[3] FATF (2014) Virtual Currencies Key Definitions and Potential AML/CFT Risks. 2014.6.

[4] Huang, Z.Y. (2015) Is It Money Laundering Case Study of China Union Pay Scandal from the Perspective of Mutual Legal Assistance on Anti-Money Laundering. Journal of Money Laundering Control, 18, 411-424.

[5] Dowers, K. and Palmreuther, S. (2003) Developing an International Consensus to Combat Money Laundering and Terrorism Financing. Infrastructure and Financial Markets Review, 9, 1-7.

[6] Schneider, F. (2010) Turnover of Organized Crime and Money Laundering: Some Preliminary Empirical Findings. Public Choice, 144, 473-486. http://dx.doi.org/10.1007/s11127-010-9676-8

[7] Kumar, V.A. (2012) Money Laundering: Concept, Significance and Its Impact. European Journal of Business and Management, 2, 113-119.

[8] Brigitte Unger, J.H. (2012) Water Always Finds its Way: Identifying New Forms of Money Laundering. Crime, Law and Social Change, 57, 287-304. http://dx.doi.org/10.1007/s10611-011-9352-z

[9] Federal Reserve System (2011) The 2010 Federal Reserve Payment Study: Non cash Payment Trends in the United States 2006-2009. 5 April 2011.

[10] Egmont Group (2014) Egmont Group of Financial Intelligence Units Annual Report 2012-2013. Toronto. 